\title{
ANALISA PENGARUH PAJAK DAERAH DAN RETRIBUSI DAERAH TERHADAP PENDAPATAN ASLI DAERAH KOTA TANGERANG SELATAN
}

\author{
Asep Mulyana \\ Prodi Akuntansi Fakultas Ekonomi Universitas Nurtanio Bandung \\ asepdiymulyana@gmail.com
}

\begin{abstract}
This research method using descriptive and verification method. Descriptive method aims to test a fairly clear picture of the object under study and draw conclusions based on research conducted. While research method verfikatif aims to estimate (estimate) and hypothesis testing (testing hypothesis). In testing the hypothesis author using the t test for the hypothesis of partial and simultaneous $F$ test for the hypothesis. While statistical tools such as regression, correlation, and a determination made through SPSS for Windows 20.0, by first doing a classic assumption test including normality test, autocorrelation, multicollinearity, and heteroscedasticity.
\end{abstract}

\section{PENDAHULUAN}

Indonesia merupakan Negara yang terbagi atas beberapa provinsi dan setiap provinsi terdiri atas daerah-daerah kabupaten/kota yang juga setiap kabupaten/kota memiliki pemerintah daerah. Banyaknya daerah di Indonesia membuat pemerintah pusat sulit mengkoordinasi pemerintahan yang ada di daerah-daerah. Sehingga untuk memudahkan pelayanan dan penataan pemerintahan, maka pemerintah pusat mengubah kebijakan yang tadinya berasas sentralisasi menjadi desentralisasi yang tercantum dalam UndangUndang Nomor 22 Tahun 1999 tentang Pemerintah Daerah. Wujud dari kebijakan desentralisasi tersebut adalah lahirnya otonomi daerah.

Berikut adalah data mengenai perkembangan Pajak Daerah Kota Tangerang Selatan Periode 2010-2014:

Perkembangan Pajak Daerah Kota Tangerang Selatan

Periode 2010-2014 (Dalam Rupiah)

\begin{tabular}{|l|c|}
\hline \multicolumn{1}{|c|}{ Tahun } & Pajak Daerah \\
\hline 2010 & $89.972 .369 .871,00$ \\
\hline 2011 & $378.420 .418 .487,00$ \\
\hline 2012 & $487.364 .145 .094,00$ \\
\hline 2013 & $607.251 .022 .635,00$ \\
\hline 2014 & $864.576 .346 .012,00$ \\
\hline Jumlah & $2.427 .584 .302 .099,00$ \\
\hline Rata-Rata & $485.516 .860 .419,80$ \\
\hline Max & $864.576 .346 .012,00$ \\
\hline Min & $89.972 .369 .871,00$ \\
\hline
\end{tabular}

Sumber: Arsip Perusahaan Tahun 2014 
Berdasarkan tabel 4.1 di atas, dapat dilihat jumlah keseluruhan pajak Kota Tanggerang Selatan dari tahun 2010 sampai dengan 2014 adalah sebesar Rp. 2.427.584.302.099,00. Rata-rata pajak daerah selama 5 periode tersebut adalah sebesar Rp. 485.516.860.419,80 setiap tahunnya. Jumlah pajak tertinggi adalah tahun 2014, yaitu sebesar Rp. 864.576.346.012,00. Sedangkan jumlah pajak daerah terendah adalah tahun 2010, yaitu sebesar $R p$ 89.972.369.871,00.

Perkembangan Pajak Daerah Kota Tangerang Selatan Periode 20102014

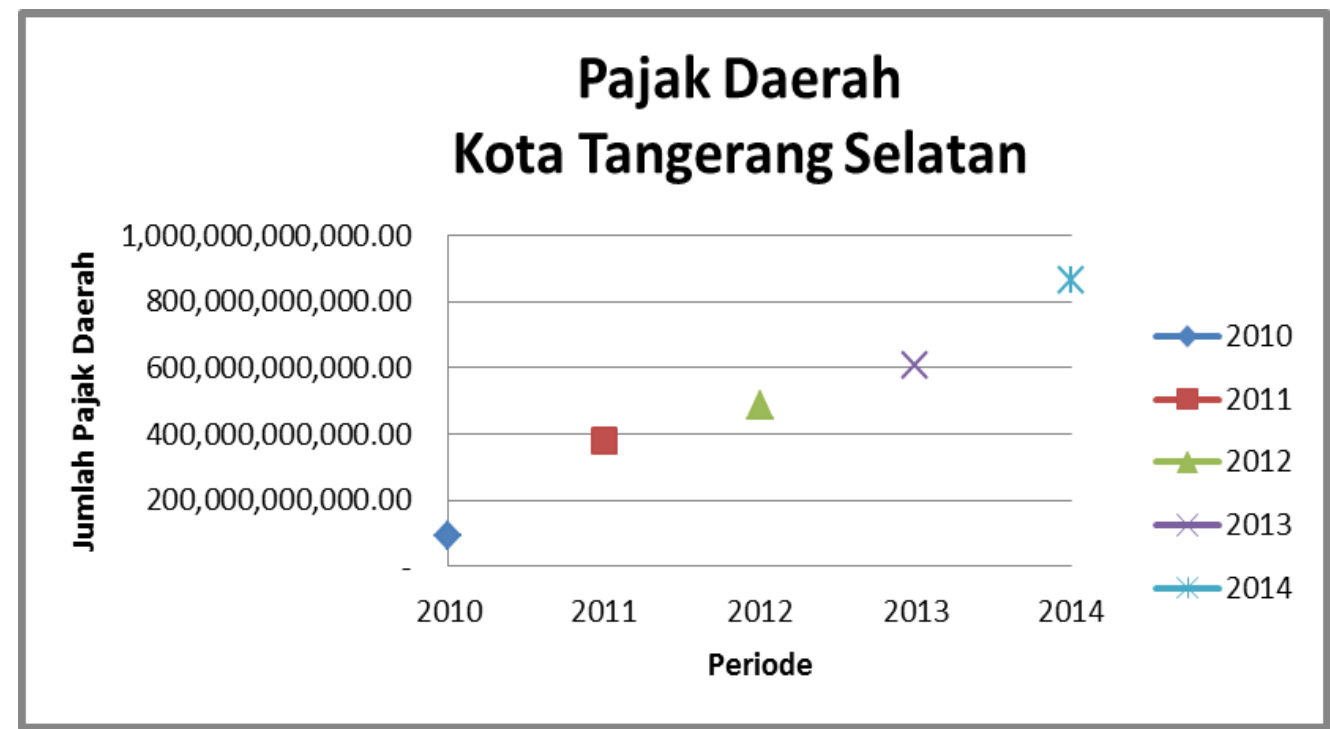

Perkembangan Retribusi Daerah Kota Tangerang Selatan Periode 20102014

Perkembangan Pendapatan Asli Daerah Kota Tangerang Selatan Periode 2010-2014 (Dalam Rupiah)

\begin{tabular}{|c|r|}
\hline Tahun & Pendapatan Asli Daerah \\
\hline 2010 & $131.503 .971 .623,00$ \\
\hline 2011 & $420.663 .048 .857,00$ \\
\hline 2012 & $576.304 .771 .005,17$ \\
\hline 2013 & $728.965 .301 .483,00$ \\
\hline 2014 & $1.023 .817 .429 .319,00$ \\
\hline Jumlah & $2.881 .254 .522 .287,17$ \\
\hline Rata-Rata & $576.250 .904 .457,43$ \\
\hline Max & $1.023 .817 .429 .319,00$ \\
\hline Min & $131.503 .971 .623,00$ \\
\hline
\end{tabular}

Sumber: Arsip Perusahaan Tahun 2014 

Perkembangan Pendapatan Asli Daerah Kota Tangerang Selatan
Periode 2010-2014

\section{Pendapatan Asli Daerah Kota Tangerang Selatan}

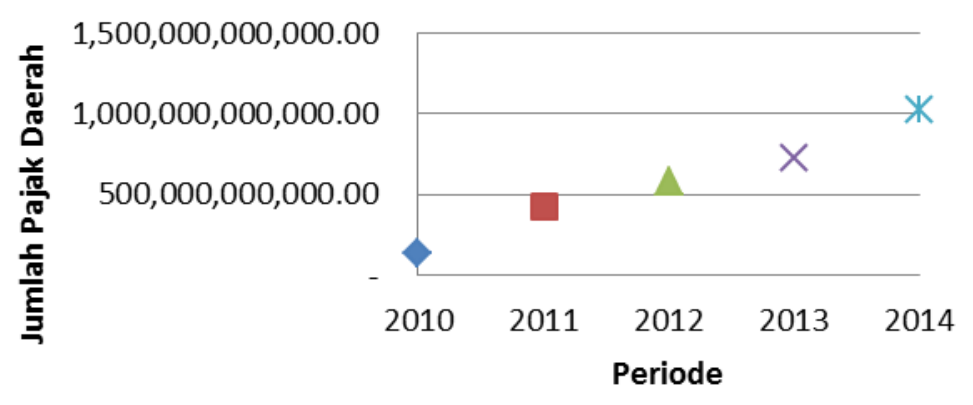

Uji Asumsi Klasik

\section{a. Uji Normalitas}

Berikut adalah hasil perhitungan uji normalitas data berdasarkan software SPSS 20 for windows:

Hasil Pengujian Normalitas

One-Sample Kolmogorov-Smirnov Test

\begin{tabular}{|c|c|c|c|c|}
\hline & & Pajak_Daerah & $\begin{array}{l}\text { Retribusi } \\
\text { Daerah }\end{array}$ & $\begin{array}{c}\text { Pendapatan_Asli_D } \\
\text { aerah }\end{array}$ \\
\hline \multicolumn{2}{|l|}{$\mathrm{N}$} & & & \\
\hline & Mean & 485516860419,8 & 62178954469,2 & 576250904457,434 \\
\hline \multirow{3}{*}{$\begin{array}{l}\text { Normal } \\
\text { Parameter } \\
\mathrm{s}^{\mathrm{a}, \mathrm{b}}\end{array}$} & Ivieant & 000 & 000 & \\
\hline & $\begin{array}{l}\text { Std. } \\
\text { Deviati }\end{array}$ & $\begin{array}{r}285671929057,8 \\
3673\end{array}$ & $\begin{array}{r}30763071753,6 \\
7503\end{array}$ & $\begin{array}{r}333783200301,155 \\
\end{array}$ \\
\hline & & 151 & 0.000 & \\
\hline Most & & 154 & ,230 & 124 \\
\hline $\begin{array}{l}\text { Extreme } \\
\text { Difference }\end{array}$ & $\begin{array}{l}\text { Positiv } \\
\text { e }\end{array}$ & 135 & 204 & , 124 \\
\hline S & $\begin{array}{l}\text { Negati } \\
\text { ve }\end{array}$ &,- 154 &,- 230 &,- 121 \\
\hline $\begin{array}{l}\text { Kolmogorov } \\
\text { Smirnov Z }\end{array}$ & & 344 & ,515 & ,276 \\
\hline $\begin{array}{l}\text { Asymp. Sig } \\
\text { tailed) }\end{array}$ & & 1,000 & ,954 & 1,000 \\
\hline
\end{tabular}

a. Test distribution is Normal.

b. Calculated from data.

Sumber: Hasil Pengolahan Data 


\section{ISSN}

Untuk menentukan dan mengetahui beberapa variabel penelitian berpengaruh normal dan tingkatannya diihat dari beberapa step dalam penelitian sesai dengan sempel penelitian

\section{b. Uji Autokorelasi} autokorelasi

Hanya untuk melihat batasaan waktu dalam penelitian melihat ada

\section{Hasil Pengujian Autokorelasi}

Model Summary

\begin{tabular}{|l|r|r|r|r|r|}
\hline Model & $\mathrm{R}$ & $\mathrm{R}$ Square & $\begin{array}{c}\text { Adjusted R } \\
\text { Square }\end{array}$ & $\begin{array}{c}\text { Std. Error of } \\
\text { the Estimate }\end{array}$ & $\begin{array}{c}\text { Durbin- } \\
\text { Watson }\end{array}$ \\
\hline 1 & $1,000^{\mathrm{a}}$ &, 999 &, 999 & $\begin{array}{r}11587733173, \\
15424\end{array}$ & 1,819 \\
\hline
\end{tabular}

\section{c. Uji Heteroskedastis}

\section{Diagram Pencar ZPRED dan SRESID}

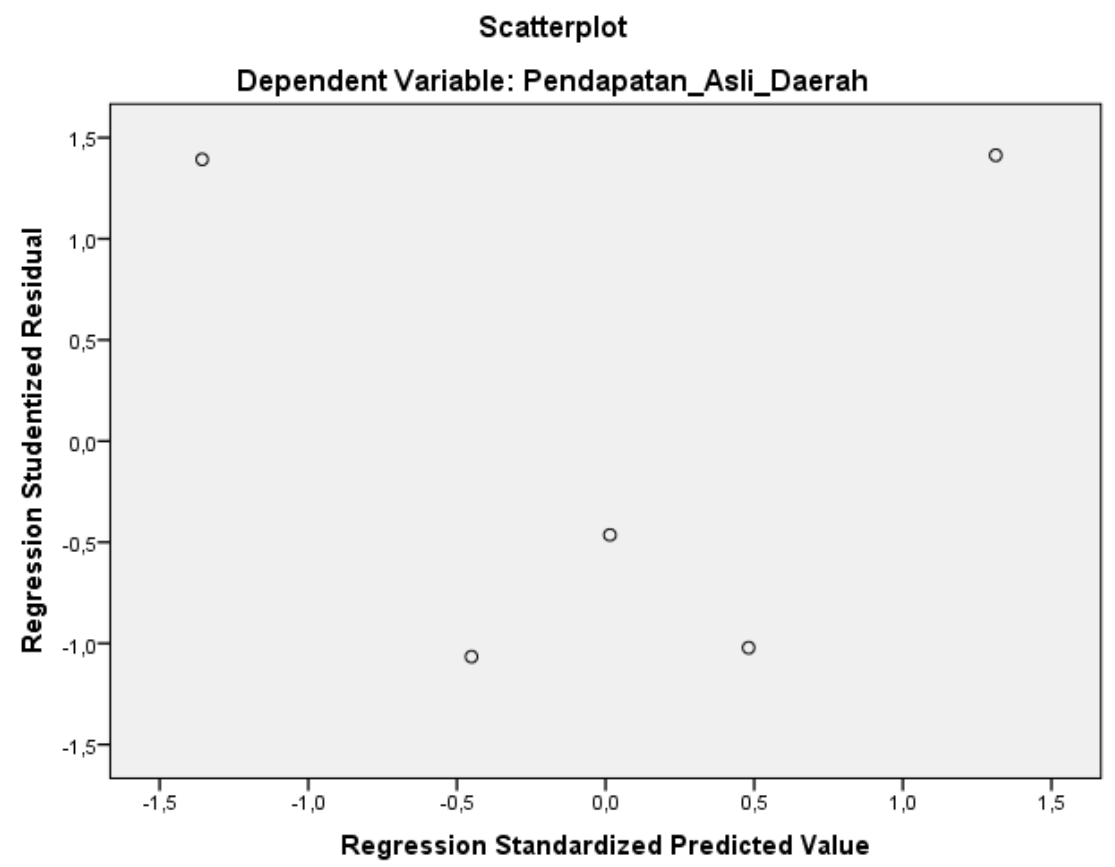

\section{Sumber: Hasil Pengolahan Data}

Plot penyebarannya tidak beraturan menunjukan dari hasil pengolahan data tersebut diatas tidak terjadi hemoskedatisitas

\section{d. Uji Multikolinearitas}

untuk mengetahui seberapa besar tingkat kesalahan dalam regresiselain itu mnegetahui hubungan variabel dalam penelitian

\section{8}




\section{Coefficients $^{\mathrm{a}}$}

\begin{tabular}{|c|c|c|c|c|c|c|c|}
\hline \multirow[t]{2}{*}{ Model } & \multicolumn{2}{|c|}{$\begin{array}{l}\text { Unstandardized } \\
\text { Coefficients }\end{array}$} & \multirow{2}{*}{$\begin{array}{c}\begin{array}{c}\text { Standardi } \\
\text { zed } \\
\text { Coefficie } \\
\text { nts }\end{array} \\
\text { Beta }\end{array}$} & \multirow[t]{2}{*}{$\mathrm{t}$} & \multirow[t]{2}{*}{$\begin{array}{l}\mathrm{Si} \\
\mathrm{g} .\end{array}$} & \multicolumn{2}{|c|}{$\begin{array}{l}\text { Collinearity } \\
\text { Statistics }\end{array}$} \\
\hline & $B$ & Std. Error & & & & $\begin{array}{c}\text { Tolera } \\
\text { nce }\end{array}$ & VIF \\
\hline (Constant) & $\begin{array}{r}8298899957 \\
, 057\end{array}$ & $\begin{array}{r}1280894650 \\
9,574\end{array}$ & & 648 & $\begin{array}{r}, 5 \\
83\end{array}$ & & \\
\hline $\begin{array}{l}1 \text { Pajak_Da } \\
\text { erah }\end{array}$ & 1,081 & ,036 & ,925 & $\begin{array}{r}29,9 \\
02\end{array}$ & $\begin{array}{l}, 0 \\
01\end{array}$ & 315 & $\begin{array}{r}3,1 \\
78\end{array}$ \\
\hline $\begin{array}{l}\text { Retribusi } \\
\text { Daerah }\end{array}$ & 960 & 336 & , 088 & $\begin{array}{r}2,85 \\
8\end{array}$ & $\begin{array}{l}1 \\
04\end{array}$ & 315 & $\begin{array}{r}3,1 \\
78\end{array}$ \\
\hline
\end{tabular}

a. Dependent Variable: Pendapatan_Asli_Daerah

\section{Analisis Regresi Berganda}

Teknik ini untuk mengetahui hasil data statistik atau pengolahan data bilamana dalam penelitian ini lebih dari dua varibel dalam penelitian.

\section{Persamaan Regresi}

Coefficients $^{\mathrm{a}}$

\begin{tabular}{|c|c|c|c|c|c|c|c|}
\hline \multirow[t]{2}{*}{ Model } & \multicolumn{2}{|c|}{$\begin{array}{l}\text { Unstandardized } \\
\text { Coefficients }\end{array}$} & \multirow{2}{*}{$\begin{array}{c}\begin{array}{c}\text { Standardi } \\
\text { zed } \\
\text { Coefficie } \\
\text { nts }\end{array} \\
\text { Beta }\end{array}$} & \multirow[t]{2}{*}{$\mathrm{t}$} & \multirow[t]{2}{*}{$\begin{array}{l}\mathrm{Si} \\
\mathrm{g} .\end{array}$} & \multicolumn{2}{|c|}{$\begin{array}{l}\text { Collinearity } \\
\text { Statistics }\end{array}$} \\
\hline & $B$ & Std. Error & & & & $\begin{array}{c}\text { Tolera } \\
\text { nce }\end{array}$ & VIF \\
\hline (Constant) & $\begin{array}{r}8298899957 \\
, 057\end{array}$ & $\begin{array}{r}1280894650 \\
9,574\end{array}$ & & ,648 & $\begin{array}{r}, 5 \\
83\end{array}$ & & \\
\hline $\begin{array}{l}1 \text { Pajak_Da } \\
\text { erah }\end{array}$ & 1,081 & ,036 & ,925 & $\begin{array}{r}29,9 \\
02\end{array}$ & $\begin{array}{l}, 0 \\
01\end{array}$ & 315 & $\begin{array}{r}3,1 \\
78\end{array}$ \\
\hline $\begin{array}{c}\text { Retribusi } \\
\text { Daerah }\end{array}$ & ,960 & ,336 & ,088 & $\begin{array}{r}2,85 \\
8\end{array}$ & $\begin{array}{l}1 \\
04\end{array}$ & 315 & $\begin{array}{r}3,1 \\
78\end{array}$ \\
\hline
\end{tabular}

a. Dependent Variable: Pendapatan_Asli_Daerah

\section{Sumber: Hasil Pengolahan Data}

Dari persamaan tersebut dapat diinterpretasikan sebagai berikut :

1. Konstanta $b_{0}=\mathbf{- 8 2 9 8 8 9 9 9 5 7 , 0 5 7}$ menyatakan bahwa harga matematis

2. Koefisien regresi $X_{1}: b_{1}=\mathbf{1 , 0 8 1}$; ini berarti jika Pajak Daerah naik satu satuan, maka Pendapatan Asli Daerah naik 1,081 satuan pada kondisi Retribusi Daerah $=0$, dan

3. Koefisien regresi $X_{2}: b_{2}=-0,960$;. 


\section{Analisis Koefisien Korelasi dan Determinasi}

Korelasi berganda untuk mengetahui hubungan variabel indevenden dan Varibel devenden atau kedua variabel tersebut kekuatan variabel tersebut.

Model Summary ${ }^{\mathrm{B}}$

\begin{tabular}{|l|r|r|r|r|r|}
\hline Model & $\mathrm{R}$ & $\mathrm{R}$ Square & $\begin{array}{c}\text { Adjusted R } \\
\text { Square }\end{array}$ & $\begin{array}{c}\text { Std. Error of } \\
\text { the Estimate }\end{array}$ & $\begin{array}{c}\text { Durbin- } \\
\text { Watson }\end{array}$ \\
\hline 1 & $1,000^{\mathrm{a}}$ &, 999 &, 999 & $\begin{array}{r}11587733173, \\
15424\end{array}$ & 1,819 \\
\hline
\end{tabular}

Sumber: Hasil Pengolahan Data

1. Menentukan tingkat signifikansi

Tingkat signifikansi yang diambil untuk penelitian ini adalah $5 \%$ dengan tarif bebas $\mathrm{db}=15-2-1=12$.

2. Menghitung nilai Fhitung

Untuk lebih jelasnya dapat dilihat pada tabel dibawah ini:

ANOVA $^{a}$

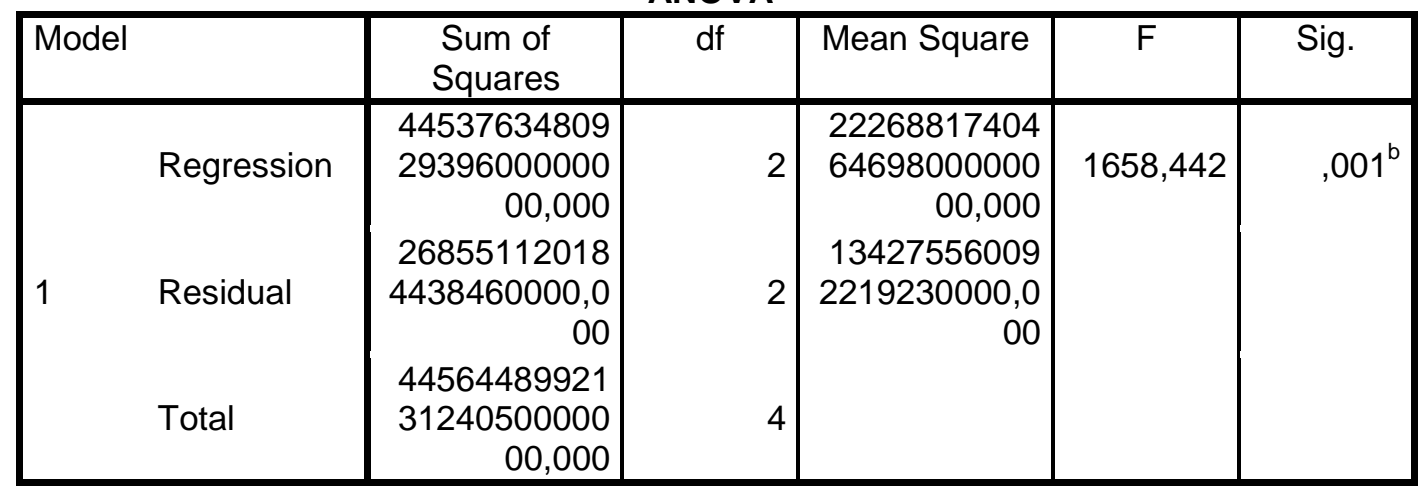

\section{Sumber: Hasil Pengolahan Data}

Pada tabel diatas diketahui Fhitung sebesar 1658,442.

Hasil $\mathrm{F}$ hitung dibandingkan dengan $\mathrm{F}$ tabel dengan kriteria:

1. $H_{o}$ ditolak jika $F_{\text {hitung }} \geq F_{\text {tabel }}(k ; d b ; 0,05)$

2. $\mathrm{H}_{\mathrm{o}}$ diterima jika $\mathrm{F}_{\text {hitung }}<\mathrm{F}_{\text {tabel }}(\mathrm{k} ; \mathrm{db} ; 0,05)$

Maka hasil yang diperoleh dari perbandingan $\mathrm{F}_{\text {hitung }}$ dengan $\mathrm{F}_{\text {tabel }}$ adalah $H_{0}$ ditolak karena $F_{\text {hitung }} \geq F_{\text {tabel }}$ yaitu $1658,442 \geq 3,89$ atau pengambilan keputusan (berdasarkan probabilitas) :

1. Jika probabilitas $>0,05$ maka $\mathrm{H}_{0}$ diterima.

2. Jika probabilitas $<0,05$ maka $\mathrm{H}_{\circ}$ ditolak.

Maka hasil yang diperoleh dari perbandingan probabilitas dengan tingkat signifikan adalah $\mathrm{H}_{\circ}$ ditolak karena: 0,001 $<0,05$. Kesimpulannya adalah terdapat pengaruh yang signifikan dari Pajak Daerah $\left(\mathrm{X}_{1}\right)$ dan Retribusi Daerah $\left(\mathrm{X}_{2}\right)$ terhadap Pendapatan Asli Daerah $(\mathrm{Y})$ secara simultan di Kota Tanggerang Selatan periode 2010-2014. 


\section{Daerah Penerimaan dan Penolakan Ho (uji F)}

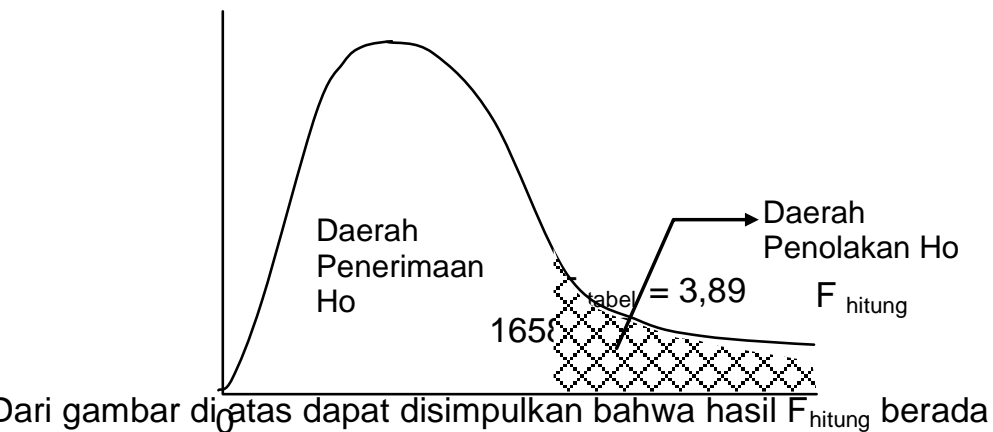
pada daerah penolakan Ho. Artinya terdapat pengaruh yang signifikan dari Pajak Daerah $\left(X_{1}\right)$ dan Retribusi Daerah $\left(X_{2}\right)$ terhadap Pendapatan Asli Daerah (Y) secara simultan di Kota Tanggerang Selatan periode 2010-2014.

\section{Kesimpulan}

Berdasarkan uji t statistik dengan menggunakan taraf nyata $5 \%$ diperoleh kesimpulan bahwa terdapat pengaruh yang signifikan dari Pajak Daerah terhadap Pendapatan Asli Daerah secara simultan. Hal ini dilihat dari $t_{\text {hitung }} \geq t_{\text {tabel }}$, yang berarti Ho ditolak.

Berdasarkan uji $t$ statistik dengan menggunakan taraf nyata 5\% diperoleh kesimpulan bahwa terdapat pengaruh yang signifikan dari Retribusi Daerah terhadap Pendapatan Asli Daerah secara simultan. Hal ini dilihat dari $t_{\text {hitung }} \geq t_{\text {tabel }}$, yang berarti Ho ditolak. Retribusi Daerah memiliki hubungan yang sangat kuat terhadap Pendapatan Asli Daerah.

\section{Saran}

Bahwa dalam penelitian dari hasil tersebut menyarankan untuk kedepannya objeklebih di perluas lagi supaya dapat menghasilkaninformasi yang lebih jelas dan meyakinkan setarap nasional bisa berguna bagi bangsa dalam hal ini adalah akademik danbagi intasi sebagai acuan atau informasi dalam pengembangan atau perbaikan dalam organisasi. 
ISSN

Jurnal Akuntansi Bisnis dan Ekonomi

2460-030X

Volume 4 No. 2, September 2017

\section{DAFTAR PUSTAKA}

Apriliasari, Evi. 2008. Pengaruh Penerimaan Pajak Daerah dan Retribusi Daerah Terhadap Pendapatan Asli Daerah Kabupaten Banyuasin periode 2010-2013 (Studi Kasus Pada Dinas Pendapatan Kabupaten Banyuasin).

Ghozali, Imam. 2011. Aplikasi Analisis Multivariate dengan Program IBM SPSS 19. Badan Penerbit Universitas Diponegoro : Semarang

Mikha, Danied. 2010. Analisis Kontribusi Pajak dan Retribusi Daerah Terhadap Pendapatan Asli Daerah Kabupaten Sleman. Kajian Akuntansi : Volume 5, Nomor 1.

Sugiyono. 2015. Metode penelitian kuantitatif, kualitatif, dan kombinasi (Mixes Methoteds). Bandung: Alfabeta

Siahaan, Marihot Pahala. 2013. Pajak Daerah dan Retribusi Daerah Berdasarkan Undang-Undang Nomor 28 Tahun 2009 tentang Pajak Daerah dan Retribusi Daerah. Rajawali Pers : Jakarta.

Samudra, Azhari Aziz. 2015. Perpajakan di Indonesia (keuangan, pajak dan retribusi daerah). RajaGrafindo Persada : Depok

http://pajak.go.id/ 